\title{
Terre à portée de main
}

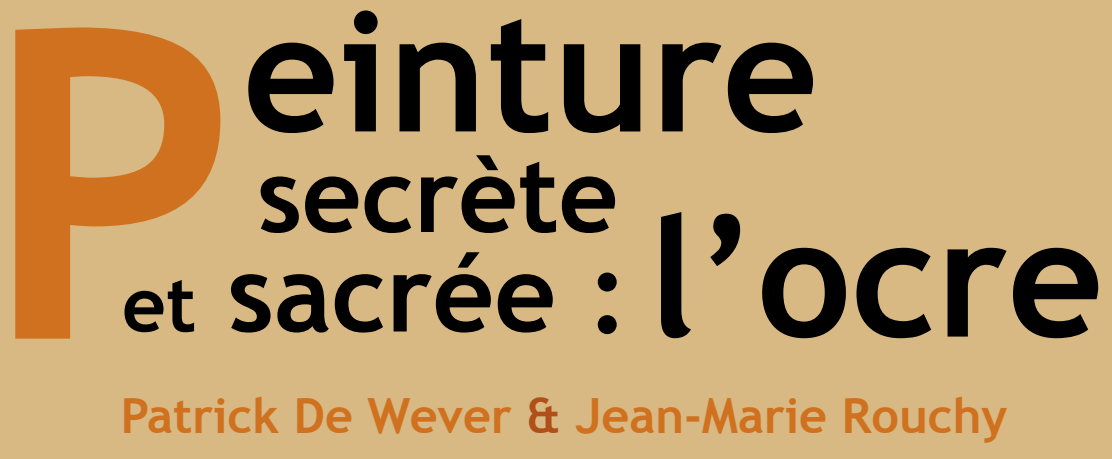

edpsciences 
Dans la même collection :

La valse des continents, P. De Wever et F. Duranthon, 2015,

ISBN : 978-2-7598-1182-3

L'eau de la vie, P. De Wever, 2015, ISBN : 978-2-7598-1189-2

Voyage d'un grain de sable, P. De Wever et F. Duranthon, 2015, ISBN : 978-2-7598-1183-0

Du vert au noir : le charbon, P. De Wever et F. Baudin, 2015, ISBN : 978-2-7598-1791-7

Terre de météorites, P. De Wever et E. Jacquet, 2015, ISBN : 9978-2-7598-1928-7

Quand la vie fabrique les roches, P. De Wever et K. Benzerara, 2016, ISBN : 978-2-7598-1978-2

Le sel, saveur de la Terre, P. De Wever et J.-M. Rouchy, 2016, ISBN : 978-2-7598-2049-8

L'énergie de la Terre, P. De Wever et H. Martin, 2017, ISBN : 978-2-7598-2104-4

Le relief de la terre, $\mathrm{P}$. De Wever et Ch. Giusti, 2017, ISBN : 978-2-7598-2233-4

\section{COLLECTION « LA TERRE À PORTÉE DE MAIN » DIRIGÉE PAR PATRICK DE WEVER}

Cette collection, dont les textes sont ponctués d'anecdotes, de petites questions et richement illustrés, est destinée à un très large public. Elle a pour vocation de présenter et de donner des notions très abordables en géologie sur les phénomènes et constituants de notre planète.

Imprimé en France

ISBN (papier) : 978-2-7598-2220-1

ISBN (ebook) : 978-2-7598-2254-6

Tous droits de traduction, d'adaptation et de reproduction par tous procédés, réservés pour tous pays. La loi du 11 mars 1957 n'autorisant, aux termes des alinéas 2 et 3 de l'article 41, d'une part, que les « copies ou reproductions strictement réservées à l'usage privé du copiste et non destinées à une utilisation collective », et d'autre part, que les analyses et les courtes citations dans un but d'exemple et d'illustration, « toute représentation intégrale, ou partielle, faite sans le consentement de l'auteur ou de ses ayants droit ou ayants cause est illicite » (alinéa $1^{\text {er }}$ de l'article 40). Cette représentation ou reproduction, par quelque procédé que ce soit, constituerait donc une contrefaçon sanctionnée par les articles 425 et suivants du code pénal. 